\title{
Exploring coral reef responses to millennial-scale climatic forcings: insights from the 1-D numerical tool pyReef-Core v1.0
}

\author{
Tristan Salles $^{1}$, Jodie Pall ${ }^{1}$, Jody M. Webster ${ }^{1}$, and Belinda Dechnik ${ }^{2}$ \\ ${ }^{1}$ Geocoastal Research Group, School of Geosciences, University of Sydney, Sydney, NSW 2006, Australia \\ ${ }^{2}$ Department of Oceanography and Ecology, Federal University of Espirito Santo, Vitoria, ES CEP-29075-910, Brazil
}

Correspondence: Tristan Salles (tristan.salles@sydney.edu.au)

Received: 5 February 2018 - Discussion started: 6 March 2018

Revised: 3 May 2018 - Accepted: 14 May 2018 - Published: 8 June 2018

\begin{abstract}
Assemblages of corals characterise specific reef biozones and the environmental conditions that change spatially across a reef and with depth. Drill cores through fossil reefs record the time and depth distribution of assemblages, which captures a partial history of the vertical growth response of reefs to changing palaeoenvironmental conditions. The effects of environmental factors on reef growth are well understood on ecological timescales but are poorly constrained at centennial to geological timescales. pyReefCore is a stratigraphic forward model designed to solve the problem of unobservable environmental processes controlling vertical reef development by simulating the physical, biological and sedimentological processes that determine vertical assemblage changes in drill cores. It models the stratigraphic development of coral reefs at centennial to millennial timescales under environmental forcing conditions including accommodation (relative sea-level upward growth), oceanic variability (flow speed, nutrients, $\mathrm{pH}$ and temperature), sediment input and tectonics. It also simulates competitive coral assemblage interactions using the generalised Lotka-Volterra system of equations (GLVEs) and can be used to infer the influence of environmental conditions on the zonation and vertical accretion and stratigraphic succession of coral assemblages over decadal timescales and greater. The tool can quantitatively test carbonate platform development under the influence of ecological and environmental processes and efficiently interpret vertical growth and karstification patterns observed in drill cores. We provide two realistic case studies illustrating the basic capabilities of the model and use it to reconstruct (1) the Holocene history (from 8500 years to present) of coral community responses to environmental changes and (2) the evolution of an ide-
\end{abstract}

alised coral reef core since the last interglacial (from 140000 years to present) under the influence of sea-level change, subsidence and karstification. We find that the model reproduces the details of the formation of existing coral reef stratigraphic sequences both in terms of assemblages succession, accretion rates and depositional thicknesses. It can be applied to estimate the impact of changing environmental conditions on growth rates and patterns under many different settings and initial conditions.

\section{Introduction}

Ecologists and geologists tend to have different spatial and temporal perspectives of coral reefs. This is because the methods and observations which inform both fields differ. While ecologists can make direct oceanographic and biological observations of coral reef ecosystems on daily to decadal timescales, reef geologists must interpret assemblage patterns from fossil outcrops and drill cores to infer persistent biological or sedimentological processes on centennial to millennial timescales. This results in both fields addressing differently the question of how coral reefs respond to environmental conditions (Stocker et al., 2013). Furthermore, as Hughes (2000) argues, the most relevant spatial and temporal scales fall in the gap between both fields; modelling predictions of climate change are most relevant to society on regional to global scales over hundreds of years.

Stratigraphic forward modelling (SFM) of carbonate systems offer a solution by simulating sedimentary processes and carbonate production through time (Burgess and Wright, 2003). In this paper, we present a deterministic, one- 
dimensional (1-D) numerical model, pyReef-Core, that simulates the vertical coral growth patterns observed in a drill core, as well as the physical and environmental processes that affect coral growth. The model is capable of integrating ecological processes like coral community interactions over centennial to millennial scales using predator-prey or generalised Lotka-Volterra equations (GLVEs). pyReef-Core is the first of its kind to incorporate coral community dynamics into reef growth modelling at reef-scale resolution. We first describe the main model constitutive laws and forcing parameters. Then we present two realistic case studies to illustrate the model's capability. First, we simulate a Holocene shallowing-up fossil reef sequence representing a "catch-up" growth strategy observed in the Great Barrier Reef (Hopley et al., 2007; Dechnik et al., 2017) and estimate assemblage compositions and changes. The second case study simulates the long-term evolution (>120000 years) of an idealised reef sequence under the influence of sea-level change and subsidence, commonly observed on passive margins worldwide (Montaggioni, 2005; Woodroffe and Webster, 2014; Gischler, 2015).

\section{SFM of carbonate systems}

SFM has become a powerful tool used to predict stratigraphic architecture of sedimentary systems (Warrlich et al., 2008). SFM involves simulating processes acting over geological timescales and iteratively refining parameters to improve the match between observed and predicted morphologies and stratigraphies. Through this trial-and-error procedure, parameters such as sedimentation and carbonate production rates can be evaluated and quantified, where they ordinarily cannot be directly observed from the fossil record (Dalmasso et al., 2001; Warrlich et al., 2008; Salles et al., 2011; Seard et al., 2013; Huang et al., 2015). In that sense, SFM addresses the shortcomings of qualitative investigation techniques applied to carbonate systems (e.g. Cabioch et al., 1999; Abbey et al., 2011; Dechnik et al., 2015). Several numerical models have been developed since the 1960s to investigate the evolution of carbonate systems; yet only recently have the complexity of biological interactions - specific to reefs - started to be addressed (Barrett and Webster, 2017; Clavera-Gispert et al., 2017).

Traditionally stratigraphic modelling of carbonatesiliciclastic systems has been applied to locate oil and gas reservoirs (Kendall et al., 1991; Burgess et al., 2006; Warrlich et al., 2008; Hill et al., 2009, 2012). However, SFM has become a popular heuristic tool to better understand and quantify parameters regulating peritidal carbonates (Burgess and Prince, 2015), the development of coral reef environments (Bosscher and Southam, 1992; Clavera-Gispert et al., 2017) as well as microbial (Parcell, 2003) and coral reef growth (Paulay and McEdward, 1990; Bosscher and Southam, 1992; Dalmasso et al., 2001). Early forward mod- els were 1-D (Schwarzacher, 1966) or 2-D in formulation (Bosence and Waltham, 1990; Kendall et al., 1991), but improvements in computing led to the development of more complex, 3-D models (e.g. Dionisos, Granjeon and Joseph, 1999; Seard et al., 2013 and FuZZIM, Nordlund, 1999).

Most recently, three software packages have been developed that represent important antecedents to the modelling effort described in this paper: CARBONATE-3D (C3D) (Warrlich et al., 2008), ReefSAM (Barrett and Webster, 2017), and SIMSAFADIM-CLASTIC (Clavera-Gispert et al., 2017). These models are 3-D and able to simulate hydrodynamic processes, sediment transport and biological production, but with varying degrees of realism. ReefSAM and C3D are both reef-scale models; yet ReefSAM constitutes an improvement from C3D in prediction of more realistic reef growth morphologies (i.e. lagoonal patch reefs and mostly sand infilled lagoons) that depends on environmental factors (Barrett and Webster, 2017). However, despite the added complexity, ReefSAM, like C3D, was found to have overly simplistic hydrodynamic and sediment transport models that were unable to simulate important, small-scale morphological features and feedbacks (Barrett and Webster, 2017).

The shortcomings of both ReefSAM and C3D are notable in their inability to model bio-sedimentary facies in any complexity. Limited to basic sedimentary facies only, they also fail to simulate how changing environmental conditions influence the ecological requirements of different coral reef communities (Clavera-Gispert et al., 2017). SIMSAFADIMCLASTIC offers the possibility to investigate carbonate production as a biological function of species interactions (based on the Lotka-Volterra equations) as well as environmental parameters (i.e. light, hydrodynamic energy and slope) (Clavera-Gispert et al., 2017). However, it has only been applied to model interactions between marine organisms and not between reef building corals. Furthermore, while the approach is promising, SIMSAFADIM-CLASTIC is not applicable at reef scales due to its coarse $>100 \mathrm{~m}$ spatial resolution and with a minimum time interval exceeding the lifespan of corals (500 years).

3-D SFM becomes necessary when accounting for the 3-D nature of sediment-driven and hydrodynamic processes like lateral reef accretion and fluid flow, establishing sediment budgets, or investigating problems such as the influence of inherited topography (Warrlich et al., 2008). However, the development of complex 3-D models has not necessarily improved the quality of carbonate system modelling. In some cases lower-dimensional and reduced-complexity models are easier to test and constrain (Paola, 2000). Because 1-D forward modelling prioritises accommodation space as the fundamental control over vertical sequences, it is a starting point to understand and constrain other essential influences on reef growth before adding greater complexity. Rationalised this way, pyReef-Core serves as a basis for constraining the biological interactive aspect of carbonate production and the ef- 


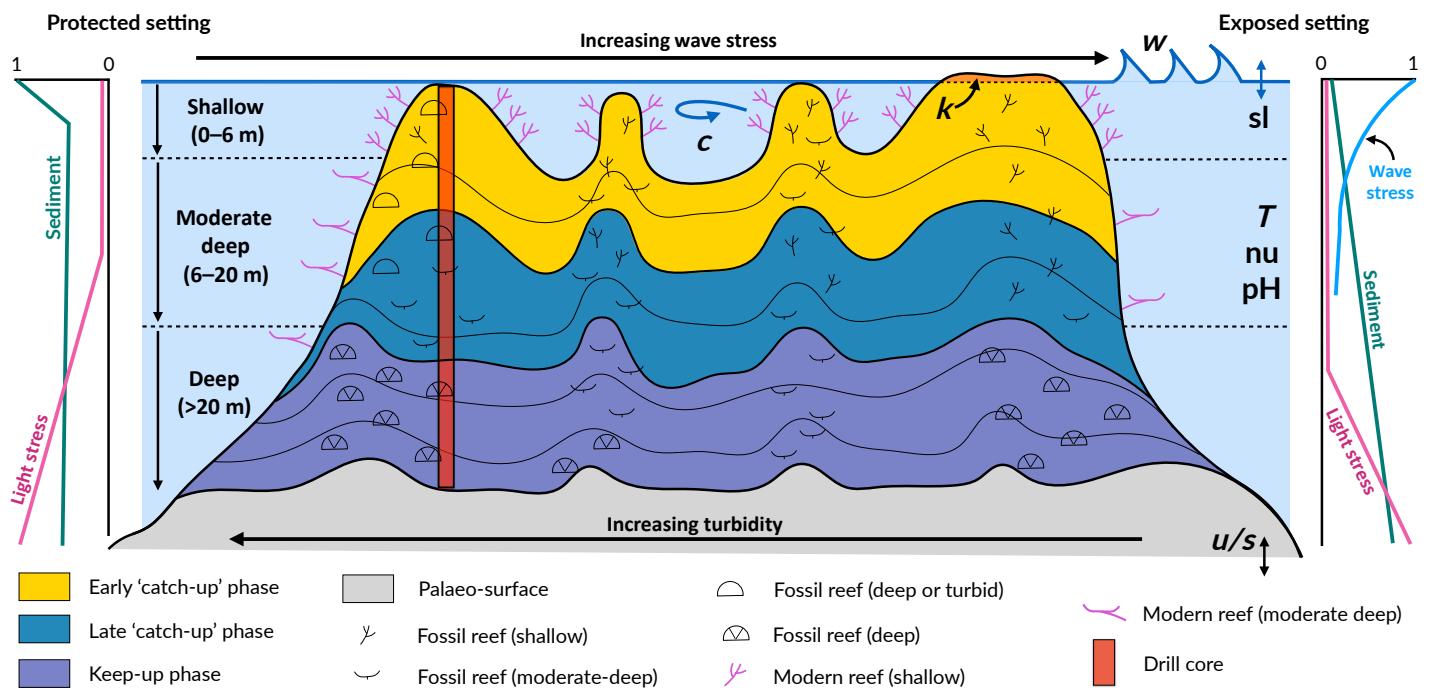

Figure 1. Schematic figure of a hypothetical reef with transitions from deep to shallow reef assemblages occurring up-core, illustrating a catch-up reef growth response to environmental forcing including light, sea-level changes (sl), hydrodynamic energy ( $w$ : wave conditions; $c$ : currents), tectonics ( $u$ : uplift; $s$ : subsidence), oceanic conditions ( $T$ : temperature; nu: nutrients; $\mathrm{pH}$ : acidification), karstification $(k)$ and sediment flux.

fect of environmental influences. Once an understanding of the complex influence of environmental conditions on vertical coral accretion can be established, extending the model to 2-D and 3-D becomes a less challenging task.

\section{Environmental controls on reef development}

Coral framework production is linked, through complicated processes, to biological activity, such that the evolution of reef systems is limited by the growth potential of carbonateproducing organisms and their environmental requirements (Flügel, 2004). Environmental factors affecting growth have been classified by Veron (2011) as latitude-correlated factors, and those that are regional or local in character. Latitudecorrelated factors include sea surface temperatures (SSTs), solar radiation and water chemistry (Kleypas et al., 1999). Regional and local environmental factors include wave climate, salinity, water clarity, nutrient influx, sedimentation regime and depth/composition of the initial substrate. These factors affect coral species to different extents, controlling the distribution of coral communities across a reef (Hallock, 2001). Over longer timescales, they also shape the rate of calcium-carbonate production, framework building by corals and the accumulation of sedimentary deposits (Done, 2011).

Despite the significant, short-term impacts cyclonic storms and terrigenous sediment input can have on reef systems (Cubasch et al., 2013), episodic disturbances are smoothed out on geologic scales (10000s years) where reef systems are characterised by remarkable persistence and resilience (Precht and Aronson, 2016). The persistent factors (e.g. sedimentation, wave climate and accommodation) are those that exert a stronger effect on the distribution of coral communities across a reef (Fig. 1). In the current study, we focus on these three main controls; however, the model can simulate the impact of other ocean forcings (temperature, nutrients and $\mathrm{pH}$ ) on coral reef development.

\subsection{Accommodation}

The effect of accommodation on coral growth is governed by the relationship between the rate of vertical reef accretion, sea-level rise, subsidence and uplift (Woodroffe and Webster, 2014). Accommodation affects coral growth in two ways (Davies et al., 1985; Braithwaite, 2016). Firstly, light attenuates with depth in the ocean, and as corals are photosynthetic organisms, carbonate production decreases exponentially with increasing water depth (Neumann and Macintyre, 1985; Schlager, 2005). Secondly, wave energy and water flow also decrease with depth, such that corals growing with reduced accommodation (i.e. in shallow depth) experience increased hydrodynamic energy (Montaggioni, 2005). The effect of light is assumed to dominate over the effect of water movement in limiting carbonate production (Dullo, 2005) (Fig. 1); however, both effects play a role in determining coral composition and, in turn, rates of vertical accretion (Cabioch et al., 1999; Kayanne et al., 2002).

\subsection{Hydrodynamic energy}

Currents, water flow and oscillatory motion induced by waves are critical in modulating physiological processes in coral and thus influencing coral growth rates (Falter et al., 2004; Lowe and Falter, 2015). High water flow increases 
rates of photosynthesis by symbiotic algae (Bruno and Edmunds, 1998), nutrient uptake by corals (Weitzman et al., 2013) and particle capture (Houlbrèque and Ferrier-Pagès, 2009) and facilitates sediment removal from coral surfaces (Rogers, 1990), all of which contribute to enhanced primary production. At the extremes, too little flow can be lethal in corals by inducing anaerobiosis, whereas extreme wave events cause mechanical destruction (Done, 2011) and can lead to long-term changes in community diversity and structure (Madin and Connolly, 2006).

Wave energy is largely dissipated on shallow reefs from bottom friction and wave breaking, with the former effect dominating the latter on reefs with high surface rugosity of coral communities (Grossman and Fletcher, 2004; Lowe and Falter, 2015; Rogers et al., 2016). Furthermore the geomorphology and high rugosity of reefs cause wave refraction, such that wave energy is highest on the ocean-facing margin (Fig. 1, exposed setting) and lower in back-reef (Fig. 1, protected setting) lagoonal and marginal environments that are protected from the prevailing winds and wave energy (Harris et al., 2015, 2018). As a result, wave-induced bottom stress strongly influences coral cover and community composition, with a clear zonation pattern from the reef crest to the reef slopes (Done, 1982; Kuffner, 2001).

\subsection{Sediment input}

High fluxes of both terrigenous and autochthonous sediments are widely identified to have both direct and indirect inhibitory effects on coral reef growth (Larcombe et al., 2001; Erftemeijer et al., 2012; Sanders and Baron-Szabo, 2005; Salles et al., 2018a). For instance, elevated turbidity on midouter platform reefs caused by the suspension of sediment on the Pleistocene reef substrate during initial flooding $\sim 9 \mathrm{ka}$ is hypothesised to be responsible for a delayed initiation of coral growth in the southern Great Barrier Reef (GBR) (Dechnik et al., 2015; Salles et al., 2018b). Autochthonous carbonate gravels and sediments (i.e. aragonite, calcite and high-magnesium calcite), produced by the growth and mechanical destruction of reef organisms through physical, biochemical and bio-erosive processes, are important determinants of the spatial and temporal distribution of coral communities on long timescales (Camoin et al., 2012; Kench, 2011). The spatial variation in suspended sediment loads is a critical environmental factor influencing coral community distribution across the reef and with depth (Perry and Larcombe, 2003) (Fig. 1). Turbid conditions are inimical to certain communities such as shallow-water corals; yet some species and communities are tolerant of elevated turbidity conditions on leeward rims (Dechnik et al., 2015) or species that thrive on reef slopes at depth (Perry et al., 2008). Hence, the spatial variation in turbidity is reflected in coral community distribution both across the reef and with depth.

Decades of experimentation carried out on the sensitivity of particular species to sediment have informed a generic understanding of the threshold levels of corals to the effect of natural sedimentation (Hubbard, 1986; Rogers, 1983; Stafford-Smith, 1993); however, these thresholds have only been partially quantified in the literature, and tolerance at the assemblage level is difficult to constrain due to site and within-species variations (Erftemeijer et al., 2012). It has been shown that even under uniform sediment input regimes, inter and intra-site variations in sedimentationresuspension regimes occur depending on water depth and exposure to wave energy (Wolanski et al., 2005). Early measurements supported that sedimentation rates exceeding $50 \mathrm{mg} \mathrm{cm}^{2}$ day $^{-1}$ produced lethal effects (Rogers, 1990). Yet each coral species has its own tolerance threshold to sediment stress, beyond which sedimentation produces sublethal to lethal effects (Erftemeijer et al., 2012).

\section{4 pyReef-Core model}

We present a 1-D deterministic, carbonate stratigraphic forward model called pyReef-Core that simulates vertical reef sequences comparable to those found in actual fossil reef drill cores. pyReef-Core is a tool to represent how dynamic biological and physical processes interact to create predictable, stratigraphic patterns. As shown in Fig. 2, the main steps in our workflow are as follows: (i) using real geological, geophysical and ecological data to establish environmental boundary conditions, vertical accretion rates of coral assemblages and defining assemblage tolerance thresholds to environmental factors and (ii) defining model input parameters including Malthusian and assemblage interaction matrix parameters, simulation time and those that define model resolution; before (iii) running the model to create a vertical core sequence that records assemblage changes and growth history.

\subsection{Vertical reef accretion module}

Carbonate production in a 1-D context, as represented by pyReef-Core, refers to the thickness of calcium carbonate produced in a core due to vertical framework accretion that is a result of vertical coral growth and sediment supply (Spencer, 2011). Hence, in this context carbonate production corresponds to reef vertical accretion. The model does not consider the destructional processes that occur on the reef due to physical, chemical and biological erosion but does account for erosional process during phases of subaerial exposure (referred as karstification in the model).

In our model, carbonate production is calculated for each time step at a user-defined resolution based on (i) the maximum vertical accretion rate for each assemblage; (ii) GLVEs determining assemblage populations; and (iii) the environmental conditions that define optimal growth for each assemblage. During periods of subaerial exposure, karstification occurs at a uniform rate independent of the type of assem- 
blages and consists in eroding reef stratigraphic top layers to the extent of the undergoing erosion.

In palaeoenvironmental analysis of real drill cores, assemblages are defined based on the relative abundance of coral species observable at certain intervals (Dechnik et al., 2015). To reflect this in our code, each depth interval in the modelled core records the assemblage that generated the greatest proportion of calcium carbonate at each time step; otherwise, if carbonate sedimentation (defined as a depth-dependent sediment input function - Fig. 2) dominates coral production, sediment characterises the depth interval.

\subsection{Generalised Lotka-Volterra equations (GLVEs)}

The predator-prey ecological model by Lotka (1920) and Volterra (1926) is a well-known and simple model of species population dynamics. Its generalised formulation (GLVEs) allows for an unlimited number of species and their pair-wise interactions and is included here to simulate coral assemblage interaction dynamics. GLVEs applied to finding the evolution of species populations typically focus on ecologically relevant periods ( $<5$ years). The application of GLVEs for this problem is to simulate changes in coral assemblages observed in drill cores, where population dynamics are not the focus but only a means to estimate production rates over geologically significant periods. This is based on the understanding that internal ecosystem dynamics are partially responsible for the long-term biozonation patterns preserved in fossil reef records (Montaggioni, 2005).

Populations for each coral assemblage are determined by a logistic growth and decay function and a matrix of pair-wise assemblage interactions (Fig. 2), formalised in the equation

$\frac{\mathrm{d} N_{i}}{\mathrm{~d} t}=\epsilon_{i} N_{i}+\sum_{j=1}^{c} \alpha_{i j} N_{i} N_{j}$,

where $N_{i}$ is the population of coral assemblage $i$ for $c$ number of assemblages, $\epsilon_{i}$ is the intrinsic rate of increase/decrease of assemblage $i$ (also known as the Malthusian parameter) and $\alpha_{i j}$ represents the interaction coefficient among assemblages $i$ and $j$. Assemblage populations at time step $t_{i+1}$ are proportional to both populations at $t_{i}$ $\left(N_{i}\right.$ and $\left.N_{j}\right)$ and to interaction coefficients $\left(\alpha_{i j}\right)$ (ClaveraGispert et al., 2017). The equation requires an initial population for each assemblage $N_{i}^{0}$, which is usually set to zero for all populations as the basement substrate is unpopulated at the beginning of reef initiation simulations. Initialisation of any assemblage populations depends on environmental conditions and is related to the "turn-on" criterion presented in Sect. 4.7. Once these conditions are met for a particular assemblage, its population number is set to 1 and will evolve following the GLVEs defined above (Eq. 1).

\subsection{Malthusian parameter $(\epsilon)$}

Assemblage populations are proportionate to a Malthusian parameter $\epsilon$ which takes values between 0 and 1 and reflects the intrinsic reproduction of species through birth and mortality of corals in ecology (Fig. 2 - Clavera-Gispert et al., 2017). However, in the geologic context of pyReef-Core, $\epsilon$ represents the tendency of corals to spatially dominate under favourable environmental conditions.

Clavera-Gispert et al. (2017) previously incorporated GLVEs to model the geological evolution of large-scale carbonate platforms and assumed that $\epsilon$ is not meaningful when timescales are beyond the lifespan of an organism and supposed that $\epsilon=1$. Clavera-Gispert et al. (2017) examine carbonate production in 500-year intervals whereas pyReefCore explores much smaller intervals ( $<10$ years), and as coral colonies may live for several decades to centuries (Camoin et al., 1997; Grigg, 2002), $\epsilon$ is not assumed to be 1. Even when assuming $\epsilon=1$, pyReef-Core simulations produced volatile population dynamics where assemblage populations grew exponentially and were unable to replicate longterm ecosystem stability nor the thousands of years of assemblage persistence observed on some reefs (Camoin et al., 1997). Hence, while values of $\epsilon$ are not yet known at the decadal scale, $\epsilon$ is an important parameter regarding spatial changes in assemblage distributions that occur within centuries. Finally, $\epsilon$ is scaled according to the environmental factors to take into account the limiting effect of inimical environmental forces on assemblage population growth (Sect. 4.6).

\subsection{Assemblage interaction matrix}

The pair-wise coefficients of interaction between assemblages can be represented as elements $\alpha_{i j}$ in a square C-by$\mathrm{C}$ matrix, where any $\alpha_{i j}$ is a special case of the effect of a change in assemblage population $N_{i}$ on itself. Values of the coefficients describe the beneficial, neutral or detrimental effects of one species on another (Table 1). As with $\epsilon$, values of $\alpha_{i j}$ cannot be inferred from previous ecological modelling studies (e.g. Clavera-Gispert et al., 2017) as the temporal scales of study are irreconcilable. It is assumed, however, that competitive-to-neutral effects control the spatial distribution and abundance of coral assemblages at decadal timescales.

Competitive interactions between corals have received considerable attention in ecology (Lang and Chornesky, 1990), especially regarding their spatial distribution outcomes. As assemblages occupy ecological niches, each will spatially dominate at a location under specific environmental conditions, outcompeting other assemblages for food, space and light (Connell et al., 2004). Hence, competition is an important determinant of reef biozonation which persists over centennial timescales given that coral growth is slow and colony lifespans can be centuries long. Hence in pyReef- 


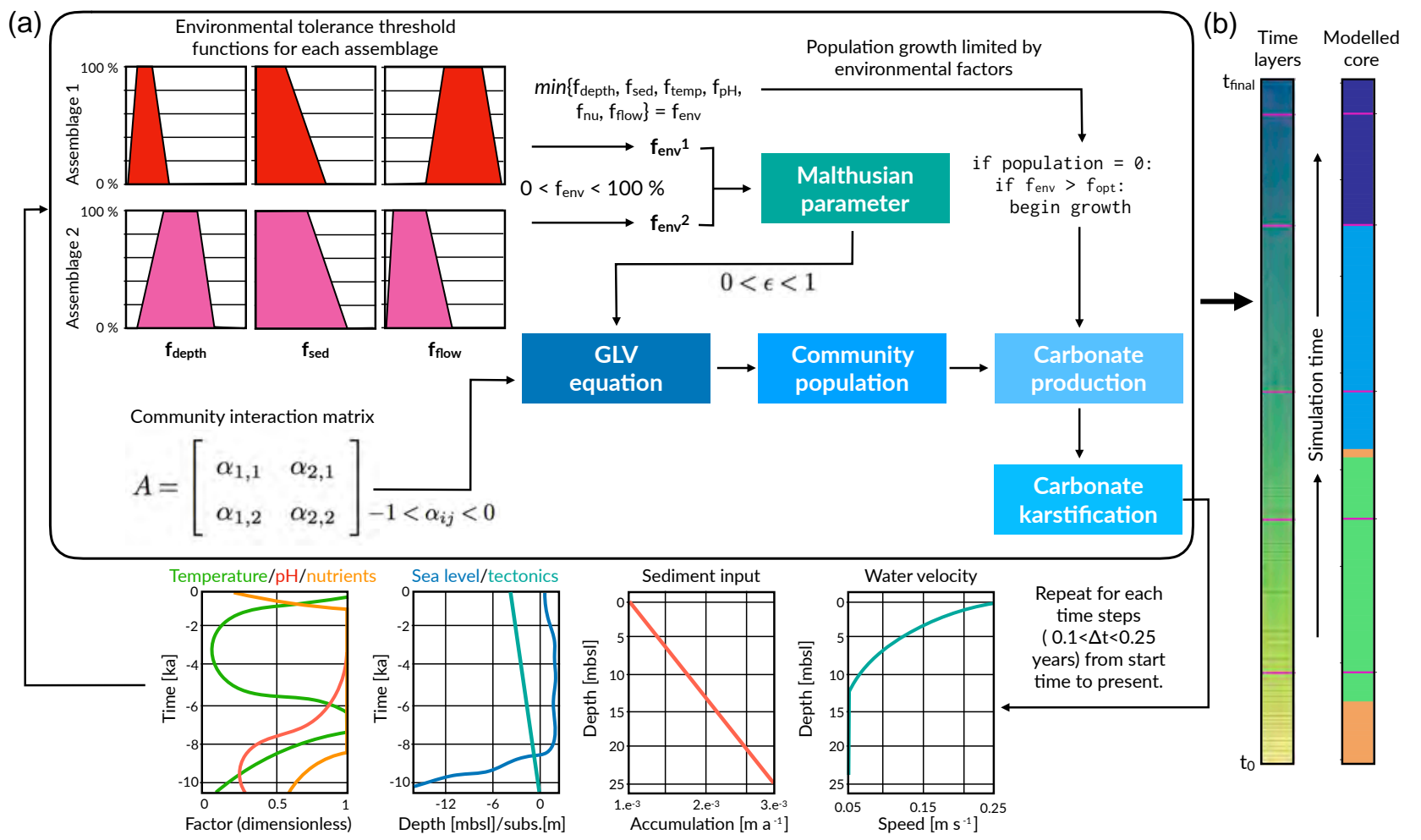

Figure 2. Illustration outlining pyReef-Core workflow (a) and of the resulting simulated core (b). First boundary conditions for sea level, sediment input and flow velocity are set, which describes their relationship to either depth or time. The boundary conditions are used to establish the environment factor $f_{\text {env }}$, which describes the proportion of the maximum growth rate that an assemblage can achieve, depending on whether the environmental conditions exceed the optimal conditions for growth. The environment factor is scaled by the Malthusian parameter, which is in turn used as input in the GLVEs to determine assemblage populations. Larger assemblage populations contribute to a faster rate of vertical accretion (here referred to as carbonate production). At the end of the time step, boundary conditions are updated and the process is repeated.

Table 1. Interaction possibilities among coral assemblages and the associated range of matrix coefficients, adapted from Clavera-Gispert et al. (2017).

\begin{tabular}{llrlr}
\hline Interactions & Effect on $i$ & $\alpha_{i j}$ range & Effect on $j$ & $\alpha_{i j}$ range \\
\hline Competition & Detrimental & $-1 \leq \alpha_{i j} \leq 0$ & Detrimental & $-1 \leq \alpha_{i j} \leq 0$ \\
Neutralism & Neutral & $\alpha_{i j}=0$ & Neutral & $\alpha_{i j}=0$ \\
\hline
\end{tabular}

Core, the interaction matrix is formed by competitive-toneutral interaction coefficients between -1 and 0 (Table 1).

\subsection{Computing carbonate production based on assemblage populations}

Solved GLVEs determine population growth/decline for each assemblage, and are used to compute carbonate production $\left(\mathrm{cm} \mathrm{yr}^{-1}\right)$ for each time step. The amount of carbonate produced by each coral assemblage during each time step is defined as

$\frac{\mathrm{d} p_{i}}{\mathrm{~d} t}=\frac{\sum_{i=1}^{c} A_{i} \times N_{i}}{S}$ where the carbonate production at every time step of each assemblage $p_{i}$ for $c$ number of assemblages is a product of the population distribution $N_{i}$ and the maximum rate of vertical accretion $A_{i}$ in proportion to a scalar $S$. The scalar is introduced to the vertical growth equation in order to minimise distortionary effects of exponential growth trends for each population occurring in the absence of inter-assemblage competition (i.e. to prevent unreasonably large population growth when only one assemblage can exist under certain conditions). Total vertical reef growth $G$ recorded in a core is the sum of carbonate sediment deposited $p_{\text {sed }}$ and all cal- 
cium carbonate produced by each assemblage:

$\frac{\mathrm{d} G}{\mathrm{~d} t}=\sum_{i=1}^{c} p_{i}+p_{\text {sed }}$

\subsection{Environmental factors}

Sediment input, water flow and accommodation are the basic environmental factors influencing coral growth in pyReefCore. However, the model architecture is such that in the future it is possible to simulate the effect of other important environmental parameters such as ocean temperature, $\mathrm{pH}$ and nutrient flux. Tolerance functions are defined for each environmental factor as a set of four points that indicates both the range in which an assemblage would reasonably exist based on published empirical data (Done, 1982; Hopley et al., 2007; Dechnik, 2016) and the rate at which vertical accretion reduces as the environmental conditions exceed upper or lower threshold limits for each assemblage (Fig. 2). As such, they define an "optimal growth window" for each assemblage. The threshold functions for each assemblage to ambient environmental conditions are combined into a single environmental parameter $f_{\text {env }}$ subject to the minimum value rule:

$f_{\mathrm{env}}=\min \left[f_{\mathrm{depth}}^{i}, f_{\mathrm{sed}}^{i}, f_{\mathrm{temp}}^{i}, f_{\mathrm{pH}}^{i}, f_{\mathrm{nu}}^{i}, f_{\text {flow }}^{i}\right]$

where $f_{\text {depth }}, f_{\text {sed }}, \ldots$ and $f_{\text {flow }}$ represent the threshold functions for each assemblage $i$. Hence, $f_{\text {env }}$ is seen as the combined effect of ambient environmental conditions on optimal growth conditions (Fig. 2). Finally, the Malthusian parameter $\epsilon$ is scaled by the environmental factor such that

$E^{i}=\epsilon \times f_{\mathrm{env}}^{i}$

which reflects the limiting effect on environmental factors on the growth potential of each assemblage.

\subsection{Turn-on criterion}

At the initialisation of the pyReef-Core simulations, assemblage populations are usually set to zero. Population growth only occurs when the initial criterion $f_{\text {env }}>f_{\text {opt }}$ is met (Fig. 2). It reflects the notion that reef turn-on events occur because of a confluence of optimal conditions including a shallow substrate, favourable energy, light and water temperature, $\mathrm{pH}$, and nutrients conditions and relatively low sediment supply (Buddemeier and Hopley, 1988; Fabricius, 2005; Dechnik et al., 2015). In other words, pyReef-Core only initiates growth when a degree of optimality in growth conditions are met. By default, the value of $f_{\text {opt }}$ is set to 0.5 which means that the turn-on criterion is met when environmental conditions enable at least $50 \%$ of the maximum vertical accretion. The parameter, however, can be adjusted within the XML input file to reflect different assemblage population sensitivities to environmental conditions.

\section{Examples of model application}

Two case studies are presented here to assess the ability of pyReef-Core to reproduce realistic sequences found in drill core. We simulate the interactions between three assemblages which are estimated based on water depth intervals (shallow, intermediate and deep). We also consider that coral production in these experiments is primarily controlled by accommodation and exposure to sedimentation (Chappell, 1980; Tudhope, 1989) and water flow (Fulton et al., 2005; Comeau et al., 2014).

\subsection{Experimental settings for model simulations}

\subsubsection{Assemblage maximum vertical accretion rates}

Maximum vertical accretion rates in the simulation are userdefined. For shallow assemblages on exposed margins, maximum vertical accretion rates $(11 \mathrm{~m} / \mathrm{kyr})$ are chosen to reflect known average rates for robust branching coral facies in high-energy environments established for the Indo-Pacific (Montaggioni, 2005). Moderate-deep assemblages represent slightly higher maximum accretion rates $(15 \mathrm{~m} / \mathrm{kyr})$ with the lowest accretion rates $(9 \mathrm{~m} / \mathrm{kyr})$ for deep assemblages. These were chosen to reflect the average accretion rates for IndoPacific tabular-branching and massive coral facies found in high-energy conditions (Montaggioni, 2005).

\subsubsection{Ecological dynamics}

pyReef-Core requires knowledge of the intrinsic rate of assemblage population growth/decline $\left(\epsilon_{i}\right)$ and the matrix coefficients $\left(\alpha_{i j}\right)$ of interactions between distinct assemblages. However, inferring ecological dynamics from ecological studies is challenging. Empirical studies of coral competition and growth are often focused at the species rather than assemblage level and explain competitive relationships qualitatively rather than quantitatively (e.g. Connell et al., 2004). Moreover, GLVEs have not been used to model coral population dynamics at the temporal resolution (centennial to millennial) we are interested in. Based on an initial sensitivity analysis, we define a set of values for the Malthusian parameter $\left(\epsilon_{i}\right)$ and interaction coefficients among assemblages $\left(\alpha_{i j}\right)$ which are summarised in Table 2. Chosen coefficients define small competitive interactions between assemblages.

The coral assemblages defined in this study largely do not share the same environmental setting and optimal growth conditions. Therefore, competitive interactions are restricted to only those assemblages that may reasonably co-exist due to overlapping depth, sediment flux or flow velocity thresholds. This translates to an interaction matrix with values only along the main diagonal and the super- and sub-diagonals. Everywhere else, interactions are set to 0 . Associated with these interactions, we define a series of critical threshold response functions for each assemblages (Fig. 3). 


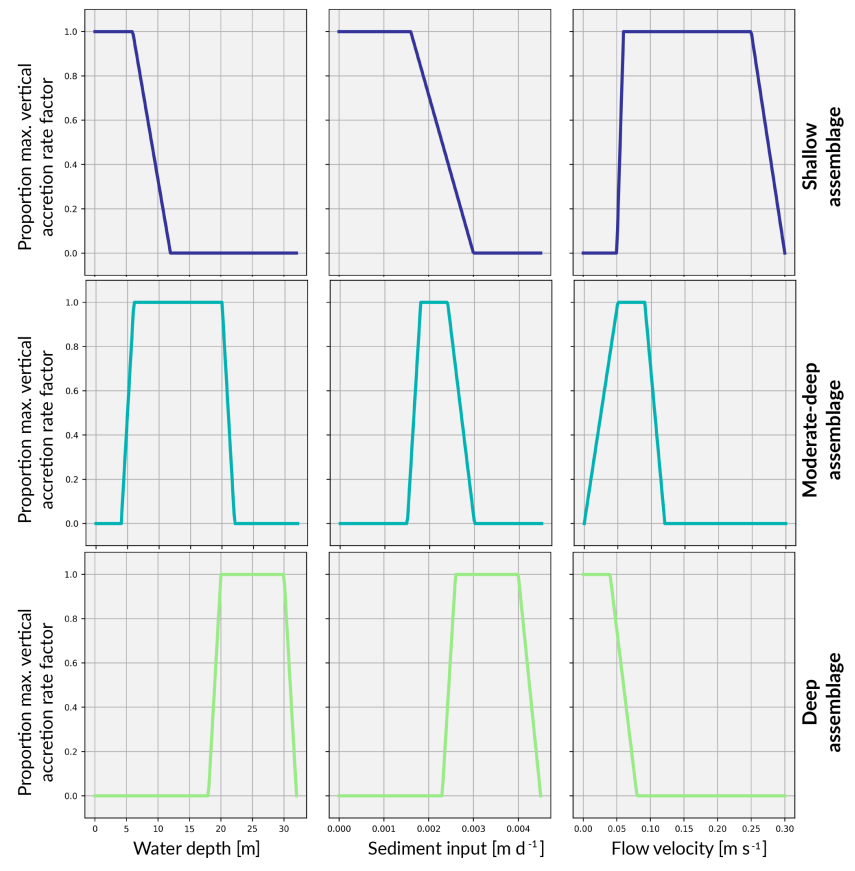

Figure 3. Environmental threshold functions for shallow, moderate-deep and deep assemblages characteristic of a synthetic exposed margin. The $x$ axis indicates the limitation on maximum vertical accretion for conditions outside the optimal maximum vertical accretion rate.

\subsubsection{Depth threshold functions}

Based on a statistical analysis of the depth and environmental distribution of modern coral communities at One Tree Reef (GBR), Dechnik et al. (2017) calibrated the palaeo-water depositional environments of six fossil coral assemblages (three in protected and three in exposed environments). This calibration was also based on quantitative measurements of crustose coralline algae thickness and vermetid gastropod abundance which are reliable palaeo-depth indicators, allowing for the depth intervals to be more accurately constrained. These assemblages are broadly consistent with shallow- and deep-water coral facies of the Indo-Pacific (Cabioch et al., 1999; Camoin et al., 2012).

Here, three assemblages typically occurring on exposed slopes are modelled according to the estimated depth intervals defined by Dechnik (2016) (Table 2) and represent shallow-water $(<6 \mathrm{~m})$, moderate-to-deep-water $(6-$ $20 \mathrm{~m})$ and deep-water $(20-30 \mathrm{~m})$ assemblages.

\subsubsection{Water flow}

The water flow function is constructed according to the theoretical relationship defined by Chappell (1980) whereby wave stress decreases exponentially with depth (Fig. 4). Here, we rely on the velocity-depth relationships on waveexposed reef slopes from the field study by Sebens et al.
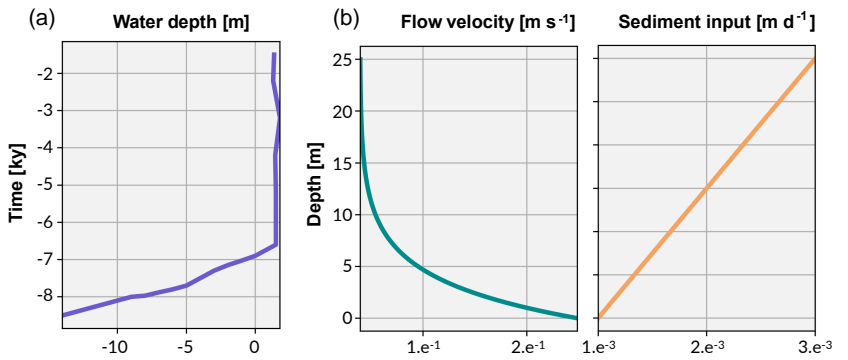

Figure 4. The curve in (a) shows the Holocene sea-level curve estimated from Sloss et al. (2007). The graphs in (b) illustrate the boundary conditions established for flow velocity and sediment input used in the experimental simulations.

(2003). A maximum velocity of $25 \mathrm{~cm} \mathrm{~s}^{-1}$ in region $\leq 1 \mathrm{~m}$ and an exponential decrease up to $25 \mathrm{~m}$ below which flow velocity is set to 0 . This is consistent with direct observations from exposed algal flat (Davies and Hopley, 1983) and maximum velocities $\left(>50 \mathrm{~cm} \mathrm{~s}^{-1}\right)$ beyond which branching corals are susceptible to breakage (Baldock et al., 2014).

With specific data on the optimal flow environment for specific corals lacking, assumptions about thresholds for distinct coral assemblages are inferred from boundary conditions. That is, the water flow exposure threshold range for each assemblage reflects the attenuation of water flow with depth (Fig. 3).

\subsubsection{Sediment exposure}

pyReef-Core can model the vertical sedimentation rate $\left(\mathrm{mday}^{-1}\right)$ as a function of either time or depth. When sediment flux is dependent on depth, it implies that sediments are autochthonous (loose carbonate materials), in contrast to terrigenous sediments transported from outside the reef system (siliclastic materials), which may be represented by sediment flux varying with time. In our case studies, we use a depthdependent sedimentation rate input curve to approximate the temporal variations in sediment accumulation along the core (Fig. 4).

Sediment tolerance thresholds for each coral assemblage (Fig. 3) are informed by Dechnik et al. (2017) before receiving maximum and minimum sedimentation rates corresponding to the sediment input boundary condition (Fig. 4). The boundary condition provides a broad indicator of the sediment load expected at certain depths and thus what would be tolerated for each depth-specific assemblage. With alternate sediment input boundary conditions, the upper and lower tolerance thresholds can be adjusted to represent how coral communities respond differently to site-specific suspended sediment levels. 
Table 2. Parameter values used in our two experiments. Estimates of maximum production rates for assemblages were determined based on literature surveys of maximum growth rates for coral facies of GBR (Davies and Hopley, 1983) and Indo-Pacific reefs (Montaggioni, 2005).

\begin{tabular}{|c|c|}
\hline Parameter & Values \\
\hline Malthusian parameter & $\epsilon_{i}=0.004$ \\
\hline \multicolumn{2}{|l|}{ Assemblage interaction matrix } \\
\hline $\begin{array}{l}\text { Main diagonal } \\
\text { Sub- and super-diagonal }\end{array}$ & $\begin{array}{l}\text { Detrimental }-\alpha_{i i}=-0.0005 \\
\text { Detrimental }-\alpha_{i j}=-0.0001\end{array}$ \\
\hline \multicolumn{2}{|l|}{ Assemblage maximum growth rate $\left(\mathrm{m} \mathrm{yr}^{1}\right)$} \\
\hline $\begin{array}{l}\text { Shallow-water assemblage }(0-6 \mathrm{~m}) \\
\text { Moderate-deep-water assemblage }(6-20 \mathrm{~m}) \\
\text { Deep-water assemblage }(20-30 \mathrm{~m})\end{array}$ & $\begin{array}{l}0.011 \\
0.012 \\
0.009\end{array}$ \\
\hline \multicolumn{2}{|l|}{ Assemblage threshold tolerance variables } \\
\hline $\begin{array}{l}\text { Shallow-water assemblage }(0-6 \mathrm{~m}) \\
\text { Absolute water flow threshold range } \\
\text { Absolute sediment input threshold range }\end{array}$ & $\begin{array}{r}0.05 \leq f_{\text {flow }} \leq 0.3 \\
0 \leq f_{\text {sed }} \leq 0.003\end{array}$ \\
\hline $\begin{array}{l}\text { Moderate-deep-water assemblage }(6-20 \mathrm{~m}) \\
\text { Absolute water flow threshold range } \\
\text { Absolute sediment input threshold range }\end{array}$ & $\begin{aligned} 0 & \leq f_{\text {flow }} \leq 0.12 \\
0.0015 & \leq f_{\text {sed }} \leq 0.003\end{aligned}$ \\
\hline $\begin{array}{l}\text { Deep-water assemblage }(20-30 \mathrm{~m}) \\
\text { Absolute water flow threshold range } \\
\text { Absolute sediment input threshold range }\end{array}$ & $\begin{array}{r}0 \leq f_{\text {flow }} \leq 0.08 \\
0.0023 \leq f_{\text {sed }} \leq 0.0045\end{array}$ \\
\hline
\end{tabular}

\subsection{Case 1: GBR idealised windward shallowing-upward Holocene reef sequence}

Based on the afore-described experimental settings, we first simulate a typical shallowing-up sequence of coral assemblages on the exposed rims of several reef in the GBR, expressing a catch-up strategy of reef growth during Holocene sea-level rise $(\sim 9.4 \mathrm{ka}$ to present $)$.

\subsubsection{Initial parameters}

Considering the simulated temporal scale, neither subsidence nor uplift are considered to be important (Hopley et al., 2007) in this experiment. Instead, accommodation is simulated as a function of Holocene sea-level changes and vertical coral reef growth only. The Holocene relative sea-level (RSL) curve from Sloss et al. (2007) is used to represent sealevel change (Fig. 4). The data suggest a RSL history that is characterised by a mid-Holocene highstand of $1.8 \mathrm{~m}$ at $\sim 4 \mathrm{ka}$ before returning slowly to present sea level, matching other estimates of RSL (Chappell, 1983; Lewis et al., 2013).

Simulation begins at $8.5 \mathrm{ka}$, which is within the take-off envelope for Holocene growth of outer-platform GBR reefs (Hopley et al., 2007). At $8.5 \mathrm{ka}, \mathrm{RSL}$ is $15 \mathrm{~m}$ below sea level (Sloss et al., 2007) and substrate is at $20 \mathrm{~m}$ depth in order to simulate a catch-up growth strategy from a deep substrate. We compute the GLVEs at time intervals of 2.5 years and combine each accumulated assemblage as a stratigraphic unit within the core for every 50 years.

\subsubsection{Communities evolution and synthetic core representation}

Figure 5 presents the GBR-representative assemblages summarised by Dechnik (2016) as well as the simulated core by pyReef-Core. The modelled core is $35 \mathrm{~m}$ long and is composed of three assemblages characteristic of an exposed margin and carbonate sediments. The simulation portrays two distinct assemblage transitions from massive assemblages representing deep (20-30 m), low-flow conditions to a fastergrowing, tabular-and-branching assemblage characteristic of the 6-20 m depth interval, which is succeeded in shallow water $(<6 \mathrm{~m})$ by a robust-branching assemblage representing higher-energy conditions (Figs. 6, 5).

As sea level rises from 8.5 to $6.5 \mathrm{ka}$, the deeper assemblages have sufficient accommodation space $(>20 \mathrm{~m})$ and low-flow to thrive. However, greater sediment input at depth is inhibitive in the early part of the simulation at the base of the core (32-35 m) (Fig. 5). As sea level begins to stabilise (Fig. 6b), accommodation space decreases and moderatedeep assemblages start to dominate the sequence up to $4.7 \mathrm{ka}$ (Fig. 6c). Following stabilisation from 4.7 to $3.2 \mathrm{ka}$, shallow assemblages develop as a result of the decreased accommodation space $(\sim 6 \mathrm{~m}$ at $4.7 \mathrm{ka})$, high-velocity hydrodynamic conditions and reduced sediment input. Assemblage growth rates (Fig. 6d) show a pattern similar to the population number curves with values lower than assemblage maximum production rates (Table 2) indicative of the effects of 
(a)

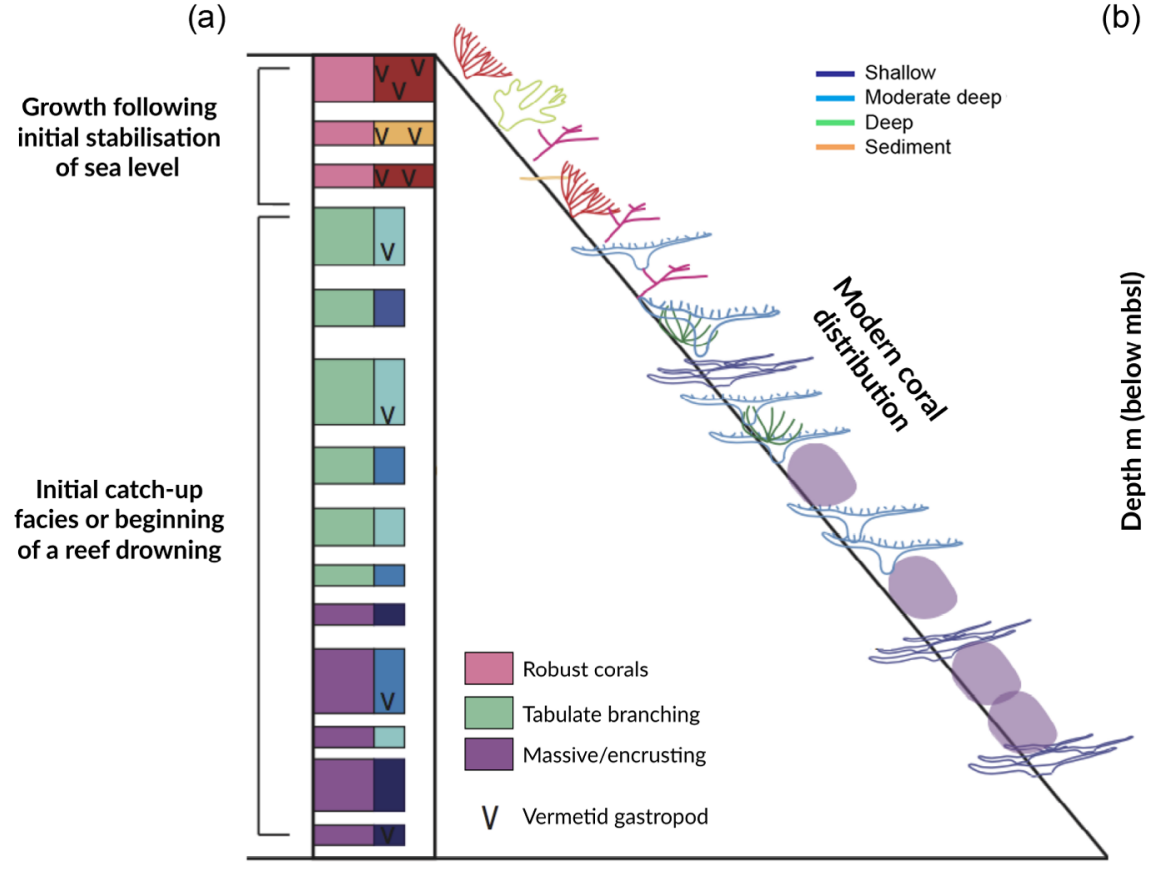

Idealised vertical fossil reef sequences on an exposed margin $\begin{array}{lll}\text { Accumulated [\%] } & \text { Time } & \text { Bio } \\ \text { facies }\end{array}$

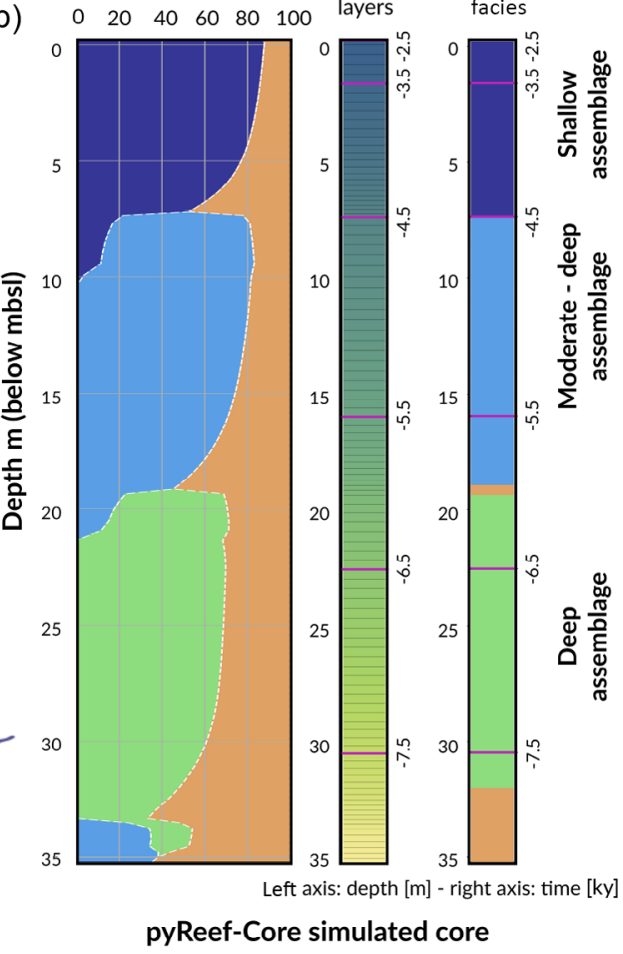

Figure 5. (a) Ideal shallowing-up fossil reef sequence representing a catch-up growth strategy with associated assemblage compositions and changes, adapted from Dechnik (2016); (b) model output of produced pyReef-Core sequence representing a similar shallowing-upward, catch-up phase.
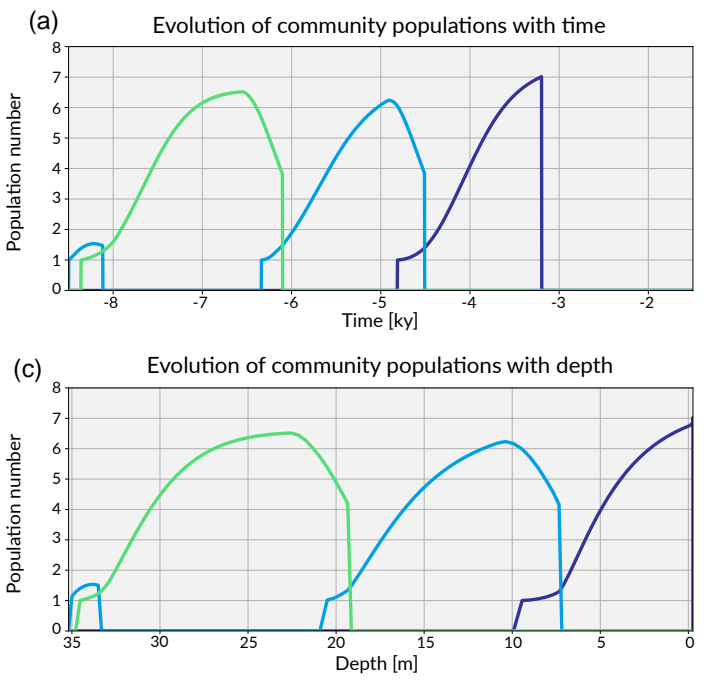

(b) Accommodation space \& core elevation through time

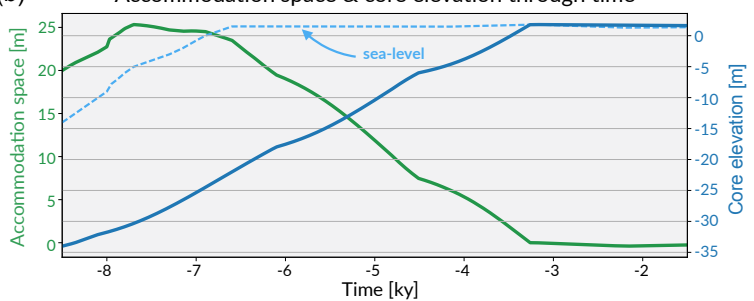

(d)
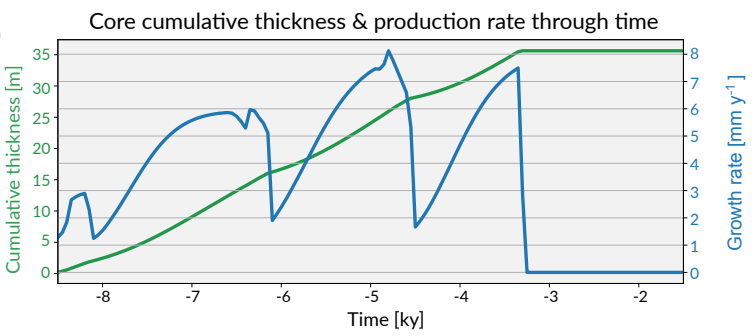

Figure 6. Graphical output from pyReef-Core showing on panels $(a, c)$ the evolution of each community in the form of population number with time and depth. As mentioned previously, population number here is a proxy for carbonate production with larger assemblage population corresponding to faster rate of vertical accretion. Panel (b) shows the evolution of the accommodation space and core elevation through time in relation to imposed sea-level curve. Panel (d) presents the temporal evolution of the cumulative thickness as well as the total coral production rate for the considered experiment. 

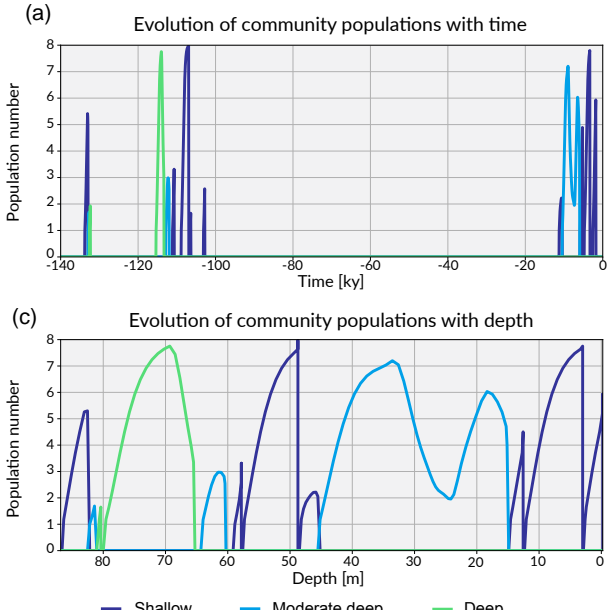

(b)

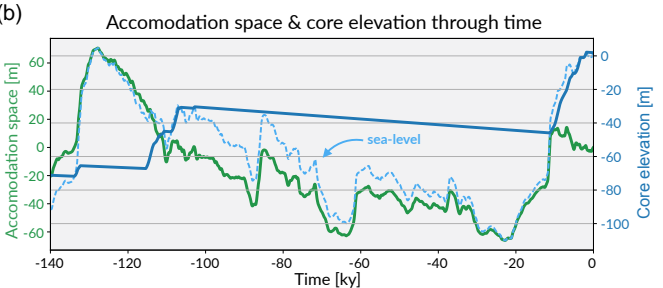

(d)

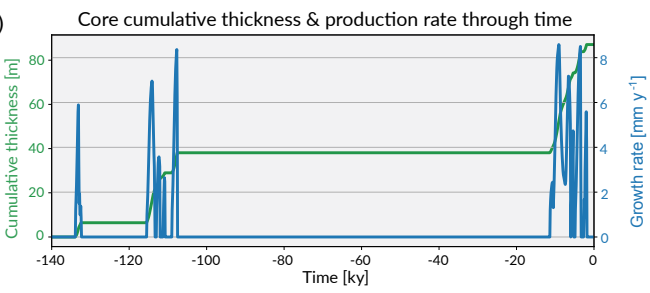

Figure 7. Similar to the previous case, these graphs shows in panels $(\mathbf{a}, \mathbf{c})$ the evolution of each community in the form of population number with time and depth. Panel (b) shows the evolution of the accommodation space and core elevation through time in relation to the imposed sea-level curve. Panel (d) presents the temporal evolution of the cumulative thickness as well as the total coral production rate.

environmental factors (sediment input and flow velocity) on the growth of each assemblage. The deeper assemblage is $15 \mathrm{~m}$ thick and is composed of $30-60 \%$ loose sediment and is succeeded by $\sim 12 \mathrm{~m}$ of moderate-deep assemblages with a lesser proportion of sediment (Fig. 5). The last 6-7 $\mathrm{m}$ of core are predominantly formed by shallow assemblages with on average less than $20 \%$ of carbonate sediments (Fig. 5). The simulated shallowing-up sequence accurately reflects expected shift from deep to moderately deep assemblages at $\sim 15-20 \mathrm{~m}$ depth and from moderately deep to shallow assemblages at $\sim 6 \mathrm{~m}$ depth proposed by Cabioch et al. (1999) and Dechnik (2016). The simulated sequence relates well to the description proposed by Dechnik (2016) and reproduces the distinct assemblages defined in the idealised reef sequences found on exposed margin along the GBR (Fig. 5).

The modelled core reaches sea level at around $2.5 \mathrm{ka}$ (Fig. 6) which also correlates well with values reported for several reefs in the GBR (Davies and Hopley, 1983; Dechnik et al., 2015; Salas-Saavedra et al., 2018). Average vertical accretion rate implied by the model is around $4.1 \mathrm{~m} \mathrm{kyr}^{-1}$ (Fig. 6), again in the range of actual drill cores average rates, which varies by around 3 to $5 \mathrm{~m} \mathrm{kyr}^{-1}$ on exposed reef margins (Davies and Hopley, 1983; Camoin et al., 2012; Dechnik et al., 2015). It is also worth noting that coral growth becomes predominant within the sequence at $\sim 7.8 \mathrm{ka}$ in the modelled core, which coheres with the observed delay in reef initiation of approximately $1 \mathrm{kyr}$ (Dechnik et al., 2015) after initial flooding of the substrate during the Holocene transgression. We also notice that the transitions between assemblages also correspond to periods where the proportion of carbonate sediment deposited increases (Fig. 5). It mimics a lag between optimal conditions from one assemblage to the other and relates to the choice of environmental threshold functions that were imposed in our simulation (Fig. 3).
Overall, the model reproduces the details of the formation of shallowing-upward sequences both in terms of assemblages succession, accretion rates, deposited thicknesses and timing of initiation. It can be applied to estimate the impact of changing environmental conditions on growth rates and patterns under many different settings and initial conditions.

\subsection{Case 2: GBR idealised reef core reconstruction over the last $140 \mathrm{kyr}$}

For the second study case, the experimental settings for threshold functions, ecological dynamics, water flow and sediment exposure (presented in Sect. 5.1) remain unchanged. The goal is not to match a specific drill core but to illustrate the influence of forcing conditions on the development of a coral reef sequence with our model.

\subsubsection{Initial parameters}

We reconstruct using pyReef-Core the evolution of an ideal coral reef sequence since the last interglacial (LIG). LIG is represented by marine isotope stage (MIS) $5 \mathrm{e}$, which is a proxy record of low global ice volume and high sea level (Grant et al., 2012). It is arbitrarily set to begin at approximately $130 \mathrm{ka}$ before present and our simulation runs over 140 kyr. The GLVEs which control the coral productions dynamic are updated every 25 years and stratigraphic layers are recorded at time interval of 100 years.

Here we use the sea-level curve proposed by Grant et al. (2012), who estimate sea-level records based on the timing of past ice-volume changes, relative to polar climate change. The relative sea-level change over the simulated period has rates of rise reaching $12 \mathrm{~cm} \mathrm{yr}^{-1}$ during all major phases of ice-volume reduction, with values below $7 \mathrm{~mm} \mathrm{yr}^{-1}$ when 
sea level exceeded present mean sea level (Grant et al., 2012). The applied sea-level curve is shown in Fig. 7b.

The karstification of Pleistocene reef limestone has been identified as a controlling factor on variations in antecedent topography, which in turn is thought to influence the morphology of modern reefs (Purdy and Winterer, 2001). Rates of karstification are a function of exposure time, rainfall, porosity and original topography of exposed carbonate reefs. Summary of karstification rates from both the Indo-Pacific and Caribbean shows values ranging from $0.01 \mathrm{~m} \mathrm{kyr}^{-1}$ (Barbados, Hopley et al., 2007) to $0.14 \mathrm{~m} \mathrm{kyr}^{-1}$ (mid-outer platform reefs, southern GBR; Marshall and Davies, 1982). Here we impose a karstification rate of $0.07 \mathrm{~m} \mathrm{kyr}^{-1}$ consistent with estimates from Ribbon Reef 5 and outer central GBR shelf (Webster, 1999).

Over such a period of time, sea-level fluctuations are not the only factor controlling the accommodation change and uplift-subsidence evolution has to be considered (Spencer, 2011). Based on a comprehensive study of GBR reefs, Dechnik (personal communication, 2017) estimates that a subsidence rate of $\sim 0.083$ to $0.13 \mathrm{~m} \mathrm{kyr}^{-1}$ is required to explain the observed elevation of the upper surface of the LIG reef that provides the antecedent topography of the modern midouter platform reefs in the GBR. The proposed range is consistent with values found for other reefs along the GBR (Marshall and Davies, 1982; Webster, 1999). In our model, we use a constant rate of subsidence set to $0.1 \mathrm{~m} \mathrm{kyr}^{-1}$ that corresponds to $14 \mathrm{~m}$ of subsidence over the duration of the simulation. In addition, the initial elevation is set $20 \mathrm{~m}$ above sea-level position at the start of the simulation (140 ka), corresponding to a depth of $\sim 70 \mathrm{~m}$ below the current sea-level position.

\subsubsection{Communities evolution and synthetic core representation}

Prior to $135 \mathrm{ka}$, the model shows a first stage of reef growth characterised by shallow-water, high-energy coral community colonisation (Fig. 7a,c and Fig. 8), following the flooding of the antecedent platform. The cumulative thickness for this phase is $<10 \mathrm{~m}$ (Fig. 7d) and is compatible with values estimated for Ribbon Reef 5 and Heron Island (Dechnik et al., 2017).

Following this initial phase, a deepening-upward sequence occurs up to $132 \mathrm{ka}$ (Fig. 8). Again, this sequence has also been identified in a similar time interval at One Tree Reef (southern GBR) and Stanley Reef (central GBR) (Dechnik et al., 2017). A lack of significant reef framework $(<30 \%)$ characterises the stratigraphic sequence during this interval.

The rapid sea-level rise (Grant et al., 2012) during the end of the penultimate deglaciation explains the drowning event observed in the core from 128 to $118 \mathrm{ka}$ (Fig. 7c). During this period, the accommodation increase is mainly driven by sea-level fluctuations and to a small extent $(\sim 1 \mathrm{~m})$ by the imposed subsidence rate.
From 118 to $107 \mathrm{ka}$, during the first stage of the regression phase, a shallowing-upward sequence $(\sim 30 \mathrm{~m}$ thick $)$ is identified with three distinct community populations modelled over time (Fig. 7c). During this time interval, the maximum population number for the moderate-deep assemblages is relative lower $(<3)$ than for the two other assemblages $(>7)$. Consequently, the percentage of accumulated thickness for this assemblage is below $7 \%$. These assemblage transitions are primarily controlled by high-frequency sea-level variations observed in the Grant et al. (2012) curve (Fig. 7b). Minor events of karstification $(<2 \mathrm{~cm}$ of erosion) are triggered by short episodes of subaerial exposure around $110 \mathrm{ka}$. From 107.5 to $104 \mathrm{ka}$, high-energy coral communities (shallow assemblages) dominate the sequence with a maximum growth rate above $8 \mathrm{~mm} \mathrm{yr}^{-1}$ (Fig. 7d).

The following stage from 107 to $12 \mathrm{ka}$ is characterised by a period of subaerial exposure due to sea-level fall (Fig. 7d). Both subsidence and karstification occur and account for nearly $11 \mathrm{~m}$ of elevation offset with about $1 \mathrm{~m}$ attributed to karstification processes (Fig. 8). Applied to a real case, pyReef-Core can be used to test several scenarios with different rates of subsidence and karstification in order to explain for example the discrepancy in age-elevation data of LIG deposits observed in the GBR (Marshall and Davies, 1982; Dechnik et al., 2017). It can also be used to estimate the contribution of karst dissolution and subsidence (Hopley et al., 2007; Purdy and Winterer, 2001) with a more quantitive approach.

By $13 \mathrm{ka}$, sea level re-floods the LIG reef, and Holocene reef growth initiates $\sim 10.5 \mathrm{ka}$ in the experiment (Fig. 7). The lag $(2.5 \mathrm{kyr})$ between flooding and reef growth initiation matches well with observations for the GBR (Fabricius, 2005; Hopley et al., 2007; Camoin et al., 2012). However, the timing of the initial flooding occurs $3 \mathrm{kyr}$ earlier than what is expected for the GBR. This temporal difference is related to both sea-level variations (Grant et al., 2012) and chosen initial starting elevation of the model. The Holocene reef sequence is around $46 \mathrm{~m}$ thick (Fig. 8), which is above most of the GBR reef maximum vertical accretion thicknesses (usually $<30 \mathrm{~m}$ ) but correlates with thicknesses found in reefs from Tahiti and Huon Peninsula (Woodroffe and Webster, 2014). This Holocene sequence is first composed of more than $30 \mathrm{~m}$ of moderate-deep assemblage, which corresponds to the catch-up phase discussed in the first study case and is associated with the rapid sea-level rise. The reef accretion rate during this time interval is maximal and reaches values above $8.2 \mathrm{~mm} \mathrm{y}^{-1}$ (Fig. 7d). The remaining $\sim 15 \mathrm{~m}$ of the uppermost sequence is built of shallow assemblages that become predominant after $6 \mathrm{ka}$ when sea-level rise decreases. It is also worth noting the presence of short periods of subaerial exposure which coincide with two small karstification events (karst dissolution $<1 \mathrm{~cm}$; Fig. 8).

The total simulated core has an overall thickness $>86 \mathrm{~m}$. A complete sequence such as the one modelled here is unlikely to be found in a natural reef complex mainly due to 

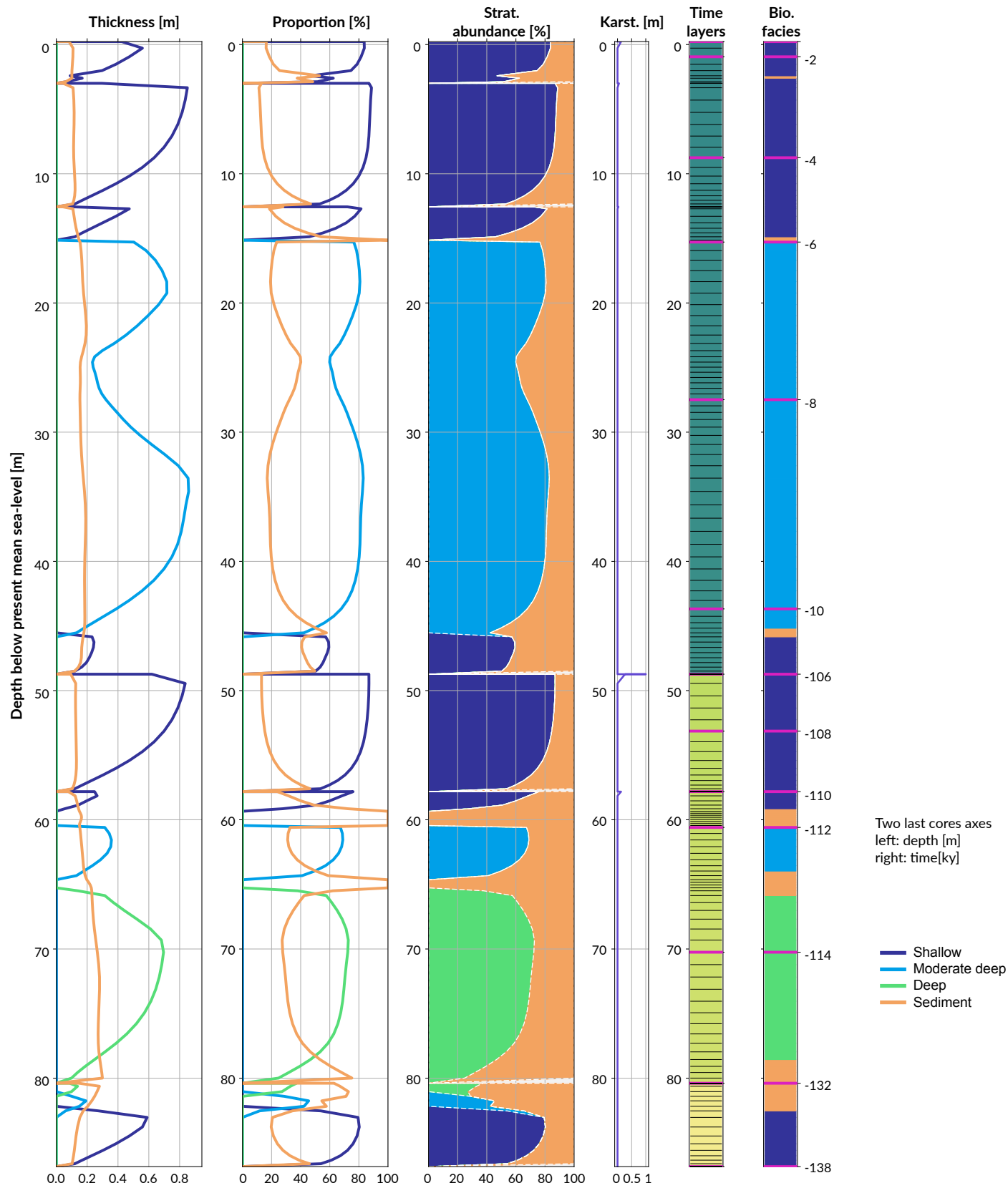

Figure 8. Simulated reef core reconstruction, showing the different stages of last interglacial reef growth in relation to sea level, karstification and subsidence.

the 3-D nature of such a system (Woodroffe and Webster, 2014). Nevertheless the predicted sequence represents in 1$\mathrm{D}$ the idealised succession of coral assemblages produced for a given set of initial and forcing conditions. Therefore, it can be compared to series of drill cores at different positions along a given region and used as a quantitative approach to analyse stratigraphic responses of coral reefs to a combination of physical, biological and sedimentological processes.

\section{Discussion}

Relatively little is known about how coral reefs grow and respond to environmental conditions at temporal scales exceeding what is measurable (i.e. observational record over the last 100 years) (Hughes et al., 2017). It has been a major challenge for both geological and ecological studies to adequately capture coral reef ecological and environmental dynamics on centennial to millennial temporal scales and at reef scales (Stocker et al., 2013). Our new method, pyReef-Core, 
operates on these scales and offers a coherent, fast and effective way to predict 1-D reef core stratigraphies and assemblages changes. It can be used to improve our understanding of coral reef response to climatic and environmental changes (Done, 2011; Harris et al., 2015). The code is most useful in application to reef researchers examining the vertical distribution of coral assemblages and coral growth dynamics (Montaggioni, 2005; Camoin et al., 2012; Dechnik, 2016) by comparing outputs between modelling cores. This would enable the extrapolation of knowledge gained from examining drill cores to areas of the reef where data are scarce. It can also be used to understand environmental histories of cores where dating or classification of assemblages is difficult due to poor core recovery. Despite its 1-D limitation, the model can be applied to gain a 3-D picture of the environmental, ecological and geomorphological history of a specific reef. This can be achieved by defining multiple biological and environmental initial conditions representing, for example, the differences in assemblage types and hydrodynamic conditions between the windward and leeward margins of the reef (Cabioch et al., 1999; Dechnik et al., 2015; Salas-Saavedra et al., 2018).

Necessarily, pyReef-Core is also a simplified representation of a coral reef system and required a number of free parameters such as sediments, flow, Malthusian parameter, and community matrix parameter which need to be defined for modelling. The task of finding this set of parameters that best describes a specific reef site and core data is challenging for several reasons. Firstly, empirical estimates of environmental tolerance thresholds of given assemblages are scarce in the scientific literature making their estimation difficult (Camoin et al., 2012; Baldock et al., 2014; Dechnik et al., 2017). Therefore, results interpreted from the modelled environmental threshold represent hypotheses that must be tested and validated against additional real, physical measurements on reefs. Secondly, reefs experience a variety of natural sedimentation regimes due to the variable morphologies (Hopley et al., 2007) and flow regimes due to the position of reefs in respect to the dominant swell (Dechnik, 2016) and proximity to the coast (Larcombe et al., 2001). Consequently, it is difficult to construct a model that fully represents complex reef system dynamics simultaneously. Thirdly, the estimation of the interaction matrix coefficients and Malthusian parameters remains difficult (Clavera-Gispert et al., 2017), specifically when considering coral assemblage dynamics at the temporal scale (decadal to centennial) relevant to pyReefCore. Yet interpretations of these parameters from ecological modelling studies provide a useful guide with regard to reef biozonation and assemblage competition (Lang and Chornesky, 1990; Grigg, 2002; Connell et al., 2004). Finally, modelled vertical accretion or growth patterns in pyReefCore are non-linear reflecting the natural complexity of coral reef systems and the biological and physical interactions occurring at reef scales. It poses the problems for calibrations and the underlying uncertainties inherent in our simplified approach (Burgess and Wright, 2003; Warrlich et al., 2008; Clavera-Gispert et al., 2017). Nevertheless, our model represents a shift from the standard accommodation-forced geometrical models (Dalmasso et al., 2001; Gale et al., 2002; Burgess et al., 2006) where coral reef stratigraphy is controlled mainly by changes in sea level. Even if our approach is a simplification of natural processes, the simulated stratigraphic patterns are a sum of simultaneous, interacting tectonic, biological, physical and sedimentological processes.

pyReef-Core can be described as a multidimensional (i.e. many parameters) and multi-modal (i.e. non-unique solutions) forward model where numerous combinations of interacting parameters could potentially produce identical sequences (Burgess et al., 2006; Burgess and Prince, 2015). Given a specific reef core dataset and pyReef-Core, the task of finding the model parameter space that best describes the reef core data can be defined as the inverse modelling problem (Jessell, 2002). Mosegaard and Sambridge (2002) highlighted the importance for Monte Carlo methods in analysis of non-linear inverse problems where no analytical expression for the forward relation between data and model parameters is available. Markov chain Monte Carlo (MCMC) methods can straightforwardly quantify uncertainty in model assumptions and parameters (Andrieu et al., 2003). This is particularly useful for SFM approaches (Warrlich et al., 2008) that require optimisation techniques that lack uncertainty quantification. However, Bayesian inference methods have rarely been applied to reef modelling, despite evidence of their usefulness when handling models with complex, interrelating parameters (Gallagher et al., 2009). A useful application of such approach would involve the optimisation of environmental threshold and ecological modelling parameters and then parameterising the sediment input and fluid flow boundary conditions based on empirical measurements.

\section{Conclusions}

Bridging the gap between ecologists' and geologists' views of coral reef system dynamics is challenging. In this paper, we present pyReef-Core, a 1-D deterministic, carbonate SFM that simulates vertical reef sequences comparable to those found in actual drill cores. The model serves as a basis for investigating the relationship between the key biological processes (i.e. the function of coral assemblages interactions based on the GLVEs) involved in coral reef growth and the influence of changing environmental factors (e.g. sea level, tectonics, ocean temperature, $\mathrm{pH}$ and nutrient). The significance of the approach lies in its ability to incorporate coral community dynamics into reef growth modelling and understand the responses of coral reefs to environmental disturbances on centennial to millennial timescales at the reef scale. The exploration of these intermediate scales is crucial to better understand the enduring growth response of corals in the face of climatic and environmental changes that are 
expected to have lasting impacts on reefs into the future. As shown in the case studies, generated model predictions cohere well with data and provide a means for explaining observed assemblage patterns. It can help to better constrain the tolerance of shallow-water corals to long-term environmental disturbance and to quantify the relative dominance of sea level, tectonics, as well as hydrodynamic energy and sediment input on reef growth.

Code and data availability. The source code (written in Python 2.7.6) with examples (Jupyter Notebooks) is archived as a repository on Github and Zenodo (https://doi.org/10.5281/zenodo.1080115). The code is licensed under the GNU General Public License v3.0. The easiest way to use pyReef-Core is via our Docker container (searching for pyreef-docker on Kitematic), which is shipped with the complete list of dependencies and the case studies presented in this paper.

Competing interests. The authors declare that they have no conflict of interest.

Acknowledgements. We would like to thank the anonymous reviewer and Jon Hill for their insightful comments on the paper. Tristan Salles was supported by ARC IH130200012, Jody M. Webster was supported by ARC DP120101793, and Tristan Salles and Jody M. Webster were also supported by SREI2020 grants. This research was undertaken with the assistance of resources from the National Computational Infrastructure (NCI), which is supported by the Australian Government and from Artemis HPC Grand Challenge supported by the University of Sydney.

Edited by: Guy Munhoven

Reviewed by: Jon Hill and one anonymous referee

\section{References}

Abbey, E., Webster, J. M., and Beaman, R. J.: Geomorphology of submerged reefs on the shelf edge of the Great Barrier Reef: The influence of oscillating Pleistocene sea-levels, Mar. Geol., 288, 61-78, 2011.

Andrieu, C., De Freitas, N., Doucet, A., and Jordan, M. I.: An introduction to MCMC for machine learning, Mach. Learn., 50, 5-43, 2003.

Baldock, T. E., Golshani, A., Callaghan, D. P., Saunders, M. I., and Mumby, P. J.: Impact of sea-level rise and coral mortality on the wave dynamics and wave forces on barrier reefs, Mar. Pollut. Bull., 83, 155-164, 2014.

Barrett, S. J. and Webster, J. M.: Reef Sedimentary Accretion Model (ReefSAM): Understanding coral reef evolution on Holocene time scales using 3D stratigraphic forward modelling, Mar. Geol., 391, 108-126, 2017.

Bosence, D. and Waltham, D.: Computer modeling the internal architecture of carbonate platforms, Geology, 18, 26-30, 1990.
Bosscher, H. and Southam, J.: CARBPLAT - A computer model to simulate the development of carbonate platforms, Geology, 20, 235-238, 1992.

Braithwaite, C. J. R.: Coral-reef records of Quaternary changes in climate and sea-level, Earth-Sci. Rev., 156, 137-154, 2016.

Bruno, J. F. and Edmunds, P. J.: Metabolic consequences of phenotypic plasticity in the coral Madracis mirabilis (Duchassaing and Michelotti): the effect of morphology and water flow on aggregate respiration, J. Exp. Mar. Biol. Ecol., 229, 187-195, 1998.

Buddemeier, R. and Hopley, D.: Turn-ons and turn-offs: Causes and mechanisms of the initiation and termination of coral reef growth, Proc. 6th International Coral Reef Symposium, 8-12 August 1988, Townsville, Australia, Plenary Addressess and Status review, 1988.

Burgess, P. M. and Prince, G. D.: Non-unique stratal geometries: implications for sequence stratigraphic interpretations, Basin Res., 27, 351-365, 2015.

Burgess, P. M. and Wright, V. P.: Numerical Forward Modeling of Carbonate Platform Dynamics: An Evaluation of Complexity and Completeness in Carbonate Strata, J. Sediment. Res., 73, 637-652, 2003.

Burgess, P. M., Lammers, H., van Oosterhout, C., and Granjeon, D.: Multivariate sequence stratigraphy: Tackling complexity and uncertainty with stratigraphic forward modeling, multiple scenarios, and conditional frequency maps, AAPG Bulletin, 90, 18831901, 2006.

Cabioch, G., Camoin, G. F., and Montaggioni, L. F.: Postglacial growth history of a French Polynesian barrier reef tract, Tahiti, central Pacific, Sedimentology, 46, 985-1000, 1999.

Camoin, G. F., Colonna, M., Montaggioni, L. F., Casanova, J., Faure, G., and Thomassin, B. A.: Holocene sea level changes and reef development in the southwestern Indian Ocean, Coral Reefs, 16, 247-259, 1997.

Camoin, G. F., Seard, C., Deschamps, P., Webster, J. M., Abbey, E., Braga, J. C., Iryu, Y., Durand, N., Bard, E., Hamelin, B., Yokoyama, Y., Thomas, A. L., Henderson, G. M., and Dussouillez, P.: Reef response to sea-level and environmental changes during the last deglaciation: Integrated Ocean Drilling Program Expedition 310, Tahiti Sea Level, Geology, 40, 643646, 2012.

Chappell, J.: Coral morphology, diversity and reef growth, Nature, 286, 249-252, 1980.

Chappell, J.: A revised sea-level record for the last 300,000 years from Papua New Guinea, Search, 14, 99-101, 1983.

Clavera-Gispert, R., Gratacós, Ò., Carmona, A., and TolosanaDelgado, R.: Process-based forward numerical ecological modeling for carbonate sedimentary basins, Comput. Geosci., 21, 373391, 2017.

Comeau, S., Edmunds, P. J., Lantz, C. A., and Carpenter, R. C.: Water flow modulates the response of coral reef communities to ocean acidification, Scientific Reports, 4, 6681, https://doi.org/10.1038/srep06681, 2014.

Connell, J. H., Hughes, T. P., Wallace, C. C., Tanner, J. E., Harms, K. E., and Kerr, A. M.: A long-term study of competition and diversity of corals, Ecol. Monogr., 74, 179-210, 2004.

Cubasch, U., Wuebbles, D., Chen, D., Facchini, M. C., Frame, D., Mahowald, N., and Winther, J.-G.: Climate Change 2013: The Physical Science Basis. Contribution of Working Group I to the Fifth Assessment Report of the Intergovernmental Panel on Cli- 
mate Change, Cambridge University Press, Cambridge, United Kingdom and New York, NY, USA, 2013.

Dalmasso, H., Montaggioni, L. F., Bosence, D., and Floquet, M.: Numerical Modelling of Carbonate Platforms and Reefs: Approaches and Opportunities, Energ. Explor. Exploit., 19, 315345, 2001

Davies, P. J. and Hopley, D.: Growth fabrics and growth-rates of Holocene reefs in the Great Barrier-Reef, BMR J. Aust. Geol. Geop., 8, 237-251, 1983.

Davies, P. J., Marshall, J. F., and Hopley, D.: Relationship between reef growth and sea level in the Great Barrier Reef, Proceedings Of The Fifth International Coral Reef Congress. Tahiti, 27 May1 June 1985, 3, 95-103, 1985.

Dechnik, B.: Evolution of the Great Barrier Reef over the last $130 \mathrm{ka}$ : a multifaceted approach, integrating palaeo ecological, palaeo environmental and chronological data from cores, $\mathrm{PhD}$ thesis, School of Geosciences, The University of Sydney, Australia, 2016.

Dechnik, B., Webster, J., Davies, P., Braga, J., and Reimer, P.: Holocene turn-on and evolution of the Southern Great Barrier Reef: Revisiting reef cores from the Capricorn Bunker Group, Mar. Geol., 363, 174-190, 2015.

Dechnik, B., Webster, J., Webb, G. E., Nothdurft, L., Dutton, A., Braga, J.-C., Zhao, J.-X., Duce, S., and Sadler, J.: The evolution of the Great Barrier Reef during the Last Interglacial Period, Global Planet. Change, 149, 53-71, 2017.

Done, T.: Patterns in the distribution of coral communities across the central Great Barrier Reef, Coral Reefs, 1, 95-107, 1982.

Done, T.: Encyclopedia of Modern Coral Reefs: Structure, Form and Process, chap. Corals: environmental controls on growth, edited by: Hopley, D., Springer, Netherlands, Dordrecht, 2011.

Dullo, W.-C.: Coral growth and reef growth: a brief review, Facies, 51, 33-48, 2005.

Erftemeijer, P. L. A., Riegl, B., Hoeksema, B. W., and Todd, P. A.: Environmental impacts of dredging and other sediment disturbances on corals: A review, Mar. Pollut. Bull., 64, 1737-1765, 2012.

Fabricius, K. E.: Effects of terrestrial runoff on the ecology of corals and coral reefs: review and synthesis, Mar. Pollut. Bull., 50, 125146, 2005

Falter, J. L., Atkinson, M. J., and Merrifield, M. A.: Mass-transfer limitation of nutrient uptake by a wave-dominated reef flat community, Limnol. Oceanogr., 49, 1820-1831, 2004.

Flügel, E.: New Perspectives in Microfacies, Springer Berlin Heidelberg, Berlin, Heidelberg, 1-6, 2004.

Fulton, C. J., Bellwood, D. R., and Wainwright, P. C.: Wave energy and swimming performance shape coral reef fish assemblages, P. Roy. Soc. Lond. B Bio., 272, 827-832, 2005.

Gale, A. S., Hardenbol, J., Hathway, B., Kennedy, W. J., Young, J. R., and Phansalkar, V.: Global correlation of Cenomanian (Upper Cretaceous) sequences: Evidence for Milankovitch control on sea level, Geology, 30, 291-294, 2002.

Gallagher, K., Charvin, K., Nielsen, S., Sambridge, M., and Stephenson, J.: Markov Chain Monte Carlo (MCMC) sampling methods to determine optimal models, model resolution and model choice for earth science problems, Mar. Petrol. Geol., 26, 525-535, 2009.
Gischler, E.: Quaternary reef response to sea-level and environmental change in the western Atlantic, Sedimentology, 62, 429-465, 2015.

Granjeon, D. and Joseph, P.: Numerical Experiments in Stratigraphy: Recent Advances in Stratigraphic and Sedimentologic Computer Simulations, chap. Concepts and applications of a 3-D multiple lithology, diffusive model in stratigraphic modeling, edited by: Harbaugh, J. W., Watney, W. L., Rankey, E. C., Slingerland, R., Goldstein, R. H., and Franseen, E. K., SEPM Special Publication, 4, 2, https://doi.org/10.1126/sciadv.aao4350, 1999.

Grant, K. M., Rohling, E. J., Bar-Matthews, M., Ayalon, A., Medina-Elizalde, M., Ramsey, C. B., Satow, C., and Roberts, A. P.: Rapid coupling between ice volume and polar temperature over the past 150,000 years, Nature, 491, 744-747, 2012.

Grigg, R. W.: Precious corals in Hawaii: discovery of a new bed and revised management measures for existing beds, Ecol. Monogr., 64, 13-20, 2002.

Grossman, E. E. and Fletcher, C. H.: Holocene reef development where wave energy reduces accommodation, J. Sediment. Res., 74, 49-63, 2004.

Hallock, P.: Coral Reefs, Carbonate Sediments, Nutrients, and Global Change, in: The History and Sedimentology of Ancient Reef Systems, edited by: Stanley, G. D., Springer US, Boston, MA, 387-427, 2001.

Harris, D. L., Vila-Concejo, A., Webster, J. M., and Power, H. E.: Spatial variations in wave transformation and sediment entrainment on a coral reef sand apron, Mar. Geol., 363, 220-229, 2015.

Harris, D. L., Rovere, A., Casella, E., Power, H. E., Canavesio, R., Collin, A., Pomeroy, A., Webster, J. M., and Parravicini, V.: Coral reef structural complexity provides important coastal protection from waves under rising sea levels, Science Advance, 4, eaao4350 https://doi.org/10.1126/sciadv.aao4350, 2018.

Hill, J., Tetzlaff, D., Curtis, A., and Wood, R.: Modeling shallow marine carbonate depositional systems, Comput. Geosci., 35, 1862-1874, 2009.

Hill, J., Wood, R., Curtis, A., and Tetzlaff, D. M.: Preservation of forcing signals in shallow water carbonate sediments, Sediment. Geol., 275-276, 79-92, 2012.

Hopley, D., Smithers, S. G., and Parnell, K. E.: The Geomorphology of the Great Barrier Reef: development, diversity and change, Cambridge, United Kingdom, 2007.

Houlbrèque, F. and Ferrier-Pagès, C.: Heterotrophy in Tropical Scleractinian Corals, Biol. Rev., 84, 1-17, 2009.

Huang, X., Griffiths, C. M., and Liu, J.: Recent development in stratigraphic forward modelling and its application in petroleum exploration, Australian J. Earth Sci., 62, 903-919, 2015.

Hubbard, D. K.: Sedimentation as a control of reef development: St. Croix, U.S.V.I., Coral Reefs, 5, 117-125, 1986.

Hughes, T. P.: Geology and ecology of coral reefs, Trends Ecol. Evol., 15, p. 125, 2000.

Hughes, T. P., Kerry, J. T., Álvarez-Noriega, M., Álvarez-Romero, J. G., Anderson, K. D., Baird, A. H., Babcock, R. C., Beger, M., Bellwood, D. R., Berkelmans, R., Bridge, T. C., Butler, I. R., Byrne, M., Cantin, N. E., Comeau, S., Connolly, S. R., Cumming, G. S., Dalton, S. J., Diaz-Pulido, G., Eakin, C. M., Figueira, W. F., Gilmour, J. P., Harrison, H. B., Heron, S. F., Hoey, A. S., Hobbs, J.-P. A., Hoogenboom, M. O., Kennedy, E. V., Kuo, C.-y., Lough, J. M., Lowe, R. J., Liu, G., McCulloch, M. T., Malcolm, H. A., McWilliam, M. J., Pandolfi, J. M., Pears, R. J., Pratchett, 
M. S., Schoepf, V., Simpson, T., Skirving, W. J., Sommer, B., Torda, G., Wachenfeld, D. R., Willis, B. L., and Wilson, S. K.: Global warming and recurrent mass bleaching of corals, Nature, 543, 373-377, 2017.

Jessell, M.: Three-dimensional geological modelling of potentialfield data, Comput. Geosci., 27, 455-465, 2002.

Kayanne, H., Yamano, H., and Randall, R. H.: Holocene sea-level changes and barrier reef formation on an oceanic island, Palau Islands, western Pacific, Sediment. Geol., 150, 47-60, 2002.

Kench, P.: Encyclopedia of Modern Coral Reefs: Structure, Form and Process, chap. Sediment Dynamics, edited by: Hopley, D., Springer Netherlands, Dordrecht, 994-1005, 2011.

Kendall, C. G. S. C., Strobel, J., Cannon, R., Bezdek, J., and Biswas, G.: The simulation of the sedimentary fill of basins, J. Geophys. Res., 96, 6911-6929, 1991.

Kleypas, J. A., McManus, J. W., and Meñez, L. A. B.: Environmental Limits to Coral Reef Development: Where Do We Draw the Line?, American Zoologist, 39, 146-159, 1999.

Kuffner, I. B.: Effects of ultraviolet radiation and water motion on the reef coral Porites compressa Dana: a flume experiment, Mar. Biol., 138, 467-476, 2001.

Lang, J. C. and Chornesky, E. A.: Competition between scleractinian reef corals - A review of mechanisms and effects, Elsevier Science Publishing Company, Inc., Amsterdam, The Netherlands, 209-252, 1990.

Larcombe, P., Costen, A., and Woolfe, K. J.: The hydrodynamic and sedimentary setting of nearshore coral reefs, central Great Barrier Reef shelf, Australia: Paluma Shoals, a case study, Sedimentology, 48, 811-835, 2001.

Lewis, S. E.and Sloss, C. R., Murray-Wallace, C. V., Woodroffe, C. D., and Smithers, S. G.: Post-glacial sea-level changes around the Australian margin: a review, Quaternary Sci. Rev., 74, 115138, https://doi.org/10.1016/j.quascirev.2012.09.006, 2013.

Lotka, A. J.: Elements of Physical Biology, Williams and Wilkins, Baltimore, 1920.

Lowe, R. J. and Falter, J. L.: Oceanic Forcing of Coral Reefs, Annu. Rev. Mar. Sci., 7, 43-66, 2015.

Madin, J. S. and Connolly, S. R.: Ecological consequences of major hydrodynamic disturbances on coral reefs, Nature, 444, 477480, 2006.

Marshall, J. F. and Davies, P. J.: Internal structure and holocene evolution of one tree reef, southern great barrier reef, Coral Reefs, 1, 21-28, 1982.

Montaggioni, L. F.: History of Indo-Pacific coral reef systems since the last glaciation: Development patterns and controlling factors, Earth-Sci. Rev., 71, 1-75, 2005.

Mosegaard, K. and Sambridge, M.: Monte carlo analysis of inverse problems, Inverse Probl., 18, R29, https://doi.org/10.1088/02665611/18/3/201, 2002.

Neumann, A. C. and Macintyre, I. G.: Reef response to sea level rise: Keep-up, catch-up or give-up, Proceedings Of The Fifth International Coral Reef Congress, Tahiti, 27 May-1 June 1985, 3, $105-110,1985$

Nordlund, U.: FUZZIM: forward stratigraphic modeling made simple, Comput. Geosci., 25, 449-456, 1999.

Paola, C.: Quantitative models of sedimentary basin filling, Sedimentology, 47, 121-178, 2000.

Parcell, W. C.: Evaluating the Development of Upper Jurassic Reefs in the Smackover Formation, Eastern Gulf Coast, U.S.A. through
Fuzzy Logic Computer Modeling, J. Sediment. Res., 73, 498515, 2003.

Paulay, G. and McEdward, L. R.: A simulation model of island reef morphology: the effects of sea level fluctuations, growth, subsidence and erosion, Coral Reefs, 9, 51-62, 1990.

Perry, C. T. and Larcombe, P.: TMarginal and non-reef-building coral environments, Coral Reefs, 22, 427-432, 2003.

Perry, C. T., Smithers, S. G., Palmer, S. E., Larcombe, P., and Johnson, K. G.: 1200 year paleoecological record of coral community development from the terrigenous inner shelf of the Great Barrier Reef, Geology, 36, 691-694, 2008.

Precht, W. F. and Aronson, R. B.: Stability of Reef-Coral Assemblages in the Quaternary, edited by: Hubbard, D. K., Rogers, C. S., Lipps, J. H., and Stanley Jr., G. D., Springer Netherlands, Dordrecht, 155-173, 2016.

Purdy, E. G. and Winterer, E. L.: Origin of atoll lagoons, GSA Bulletin, 113, 837-854, 2001.

Rogers, C. S.: Sublethal and lethal effects of sediments applied to common Caribbean Reef corals in the field, Mar. Pollut. Bull., 14, 378-382, 1983.

Rogers, C. S.: Responses of coral reefs and reef organisms to sedimentation, Mar. Ecol. Prog. Ser., 185-202, 1990.

Rogers, J. S., Monismith, S. G., Koweek, D. A., and Dunbar, R. B.: Wave dynamics of a Pacific Atoll with high frictional effects, J. Geophys. Res.-Oceans, 121, 350-367, 2016.

Salas-Saavedra, M., Dechnik, B., Webb, G. E., Webster, J. M., Zhao, J.-X., Nothdurft, L. D., Clark, T. R., Graham, T., and Duce, S.: Holocene reef growth over irregular Pleistocene karst confirms major influence of hydrodynamic factors on Holocene reef development, Quaternary Sci. Rev., 180, 157-176, 2018.

Salles, T., Griffiths, C., Dyt, C., and Li, F.: Australian shelf sediment transport responses to climate change-driven ocean perturbations, Mar. Geol., 282, 268-274, 2011.

Salles, T., Ding, X., and Brocard, G.: pyBadlands: A framework to simulate sediment transport, landscape dynamics and basin stratigraphic evolution through space and time, PLOS ONE, 13, 1-24, $2018 \mathrm{a}$.

Salles, T., Ding, X., Webster, J. M., Vila-Concejo, A., Brocard, G., and Pall, J.: A unified framework for modelling sediment fate from source to sink and its interactions with reef systems over geological times, Scientific Reports, 8, 5252, https://doi.org/10.1038/s41598-018-23519-8, 2018b.

Sanders, D. and Baron-Szabo, R. C.: Scleractinian assemblages under sediment input: their characteristics and relation to the nutrient input concept, Palaeogeogr. Palaeocl., 216, 139-181, 2005.

Schlager, W.: Carbonate Sedimentology and Sequence Stratigraphy, SEPM Society for Sedimentary Geology, SEPM Concepts in Sedimentology and Paleontology No. 8, 200 pp., 2005.

Schwarzacher, W.: Sedimentation in Subsiding Basins, Nature, 210, 1349-1350, 1966.

Seard, C., Borgomano, J., Granjeon, D., and Camoin, G.: Impact of environmental parameters on coral reef development and drowning: Forward modelling of the last deglacial reefs from Tahiti (French Polynesia; IODP Expedition 310), Sedimentology, 60, 1357-1388, 2013.

Sebens, K. P., Helmuth, B., Carrington, E., and Agius, B.: Effects of water flow on growth and energetics of the scleractinian coral Agaricia tenuifolia in Belize, Coral Reefs, 22, 35-47, 2003. 
Sloss, C. R., Murray-Wallace, C. V., and Jones, B. G.: Holocene sea-level change on the southeast coast of Australia: a review, The Holocene, 17, 999-1014, 2007.

Spencer, T.: Encyclopedia of Modern Coral Reefs: Structure, Form and Process, chap. Glacial Control Hypothesis, edited by: Hopley, D., Springer Netherlands, Netherlands, Dordrecht, 2011.

Stafford-Smith, M. G.: Sediment-rejection efficiency of 22 species of Australian scleractinian corals, Marine Biology, 115, 229243, 1993.

Stocker, T., Qin, D., Plattner, G.-K., Tignor, M., Allen, S., Boschung, J., Nauels, A., Xia, Y., Bex, V., and Midgley, P.: Climate Change 2013: The Physical Science Basis. Contribution of Working Group I to the Fifth Assessment Report of the Intergovernmental Panel on Climate Change, Cambridge University Press, Cambridge, United Kingdom and New York, NY, USA, 2013.

Tudhope, A. W.: Shallowing-upwards sedimentation in a coral reef lagoon, Great Barrier Reef of Australia, J. Sediment. Res., 59, 1036-1051, 1989.

Veron, J. E. N.: Encyclopedia of Modern Coral Reefs: Structure, Form and Process, chap. Corals, in: Biology, Skeletal Deposition, and Reef-Building, edited by: Hopley, D., Springer Netherlands, Dordrecht, 2011.
Volterra, V.: Fluctuations in the abundance of a species considered mathematically, Nature, 118, 558-560, 1926.

Warrlich, G., Bosence, D., Waltham, D., Wood, C., Boylan, A., and Badenas, B.: 3D stratigraphic forward modelling for analysis and prediction of carbonate platform stratigraphies in exploration and production, Mar. Petrol. Geol., 25, 35-58, 2008.

Webster, J. M.: The response of coral reefs to sea level change: evidence from the Ryukyu islands and the Great Barrier Reef, PhD thesis, School of Geosciences, The University of Sydney, Australia, 328 pp., 1999.

Weitzman, J. S., Aveni-Deforge, K., Koseff, J. R., and Thomas, F. I. M.: Uptake of dissolved inorganic nitrogen by shallow seagrass communities exposed to wave-driven unsteady flow, Mar. Ecol. Prog. Ser., 475, 65-83, 2013.

Wolanski, E., Fabricius, K., Spagnol, S., and Brinkman, R.: Fine sediment budget on an inner-shelf coral-fringed island, Great Barrier Reef of Australia, Estuar. Coast. Shelf S., 65, 153-158, 2005.

Woodroffe, C. D. and Webster, J. M.: Coral reefs and sea-level change, Mar. Geol., 352, 248-267, 2014. 